\title{
Anxiety- A Major Cause of Distress during Dental Procedures
}

\section{Syeda Aafia Fathima*}

Rajiv Gandhi University of Health Sciences, Bangalore, India

*Corresponding Author: Syeda Aafia Fathima, Rajiv Gandhi University of Health Sciences, Bangalore, India.
Received: July 12, 2021

Published: August 07, 2021

(C) All rights are reserved by Syeda Aafia

Fathima.

\begin{abstract}
The most horrible feeling in the world is anxiety, which we will not wish even for our enemy. Deterioration of oral health is due to avoidance of treatment because of dental anxiety which is a major problem faced by dentists. To develop a patient-centric treatment plan the dentist along with his/her team should first understand why the patient is anxious? Assessing the level of anxiety of the patient will help the dentist develop empathy towards the patient. In this article, we will be going through the causes, symptoms and effects of dental anxiety and ways to overcome it.
\end{abstract}

Keywords: Anxiety; Distress; Dental Procedures

\section{Introduction}

The fight-or-flight response, also known as acute stress response, is a physiological reaction that happens in the presence of something that is mentally or physically terrifying [1]. Stress is a rigidity in the body and mind that tells us something about the fulfilment of our needs, the expression of our emotions, and the quality of our relations [2]. Anxiety is the body's physical response to fear [3]. Dental anxiety is the term used to describe anxious behavior, stress, or fear in a dental setting [4]. It can be triggered due to needles, drills, or the dental setting itself [4]. Dental phobia can be classified as severe dental anxiety which leads to avoidance of the dental treatment [3]. The Washington Post reported in 2015, "Roughly 5 to 10 percent of the population suffers from dental phobia, but as many as 40 to 75 percent of people experience fear and anxiety related to dentistry that contributes to postponing and canceling appointments, or avoiding the dentist altogether, according to extensive research on the subject" [5].

\section{Dental anxiety in children}

Fears and anxieties are transitory which are formed during normal child development [6]. It is seen in most cases that dental anxiety is predominantly initiated in childhood itself [7]. Though the etiology is unclear, previous traumatic experience involving pain and irregularity in visiting the dentist is related to the development of dental anxiety [7]. Dental fear is most related to increased general fear and negative influence of mother's dental fear [8]. Sources of DFA (Dental fear and anxiety) can be exogenous or endogenous. Exogenous sources of DFA include direct learning like traumatic experience and indirect learning like vicarious learning, whereas endogenous factors are internal contributory factors [6]. A study was conducted to check the dependability and authenticity of measures used to assess dental anxiety in Croatian children between the age of 5 to 15 years [9]. The findings were as follows.

An anxious child generally tends to cause dental behavioral problems demonstrating emotional, aggressive age-related behav- 


\begin{tabular}{|c|c|c|c|c|c|}
\hline Questionnaire & Filled in by & Measuring & $\begin{array}{c}\text { Number of } \\
\text { questions }\end{array}$ & $\begin{array}{c}\text { Score } \\
\text { Min-Max }\end{array}$ & Cut-off point \\
\hline CDAS & Child & Child's dental anxiety & 4 & $4-20$ & $\begin{array}{c}4-8=\text { low } \\
9-12=\text { mild } \\
13-20=\text { high }\end{array}$ \\
\hline PDAS & $\begin{array}{c}\text { Parent (Mother/ } \\
\text { Father) }\end{array}$ & Child's dental anxiety & 4 & $4-20$ & $\begin{array}{c}\text { 4-8=low } \\
9-12=\text { mild } \\
13-20=\text { high }\end{array}$ \\
\hline CMFQ & Child & Child's fear of medical treatment & 12 & $12-36$ & $\begin{array}{c}<26=\text { low } \\
26-30=\text { high }\end{array}$ \\
\hline CFSS-DS & Parent/Child & Child's dental anxiety & 15 & $15-75$ & $\begin{array}{c}<31=\text { low } \\
31-39=\text { mild } \\
>39=\text { high }\end{array}$ \\
\hline S-DAI & Child & Child's dental anxiety & 9 & $9-45$ & $\begin{array}{c}<12=\text { low } \\
12-33=\text { mild } \\
>33=\text { high }\end{array}$ \\
\hline OAS & Child & Child's aggression & 4 & $4-16$ & $\begin{array}{c}<6=\text { low } \\
6-16=\text { high }\end{array}$ \\
\hline DVSS-SV & Child & Child's satisfaction with dentist & 10 & $10-50$ & $\begin{array}{c}<35=\text { low } \\
35-50=\text { high }\end{array}$ \\
\hline ISP & Parent & Socioeconomic status of the family & & & $\begin{array}{c}\text { 11-17=very low (I) } \\
\text { 18-27=low (II) } \\
28-43=\text { mild (III) } \\
44-60=\text { high (IV) } \\
\text { 61-77=very high (V) }\end{array}$ \\
\hline
\end{tabular}

Table 1: Questionnaires used in a study of reliability and validity of measures for assessment of dental anxiety in 5-to 15-year-old Croatian children [9].

CDAS=Child's Corah Dental Anxiety Scale; PDAS=Parental Corah Dental Anxiety Scale; CMFQ=Broome's Child Medical for Questionnaire; OAS=Overt Aggression Scale; CFSS-DS=Children's Fear Survey Schedule-Dental Subscale; S-DAI=Dental Anxiety Inventory (Short Version); DVSS-SV=Dental Visit Satisfaction Scale-Swedish Version; IASP=Hollingshead Two-Factor Index of Social Position

ior like tantrums, crying, freezing, clinging etc [9]. Such nature of behavior resulting from fear is known as "childhood phobia" [9].

\section{Dental anxiety in adults}

Past research has shown that the fear and anxiety associated with dental settings are multi-factorial [10]. A dentist needs to as- sess the dental anxiety of the patient as it helps in the management of their anxiety [9]. Following are a few of the factors that cause dental anxiety:

- If they believe painful treatment is inevitable [10].

- If the patient had a painful experience in the past [10]. 
- If they feel they have no control over the situation, including stopping the procedure [10].

- If they do not understand the procedure to be performed [10].

- If they have experienced frightening portrayals of the dentists in the media [10].

- If they have experienced detached or depersonalized treatment by the dentist [10].

- If the patient is suffering from generalized anxiety, depression, or post-traumatic stress disorder [4].

Signs and symptoms of dental anxiety

A patient suffering from dental anxiety may experience the following [4]:

1. Visible distress, crying, or signs of panic.

2. Sweating.

3. Tachycardia or palpations.

4. Low blood pressure and Syncope.

5. Withdrawal from the procedure.

6. Use of humor or aggression to mask the anxiety.

\section{Effects of anxiety on oral health}

Dental treatments are generally compromised based on the anxiety levels of the patient. Various studies have demonstrated a direct correlation between dental anxiety and oral health quality in life (OHQOL) [11]. Fearful dental patients have poorer oral and periodontal health when compared to the patients of the same age [12]. Dental anxiety and fear are one of the reasons that general dentists hesitate to perform aggressive clinical interventions on young children [13]. These conditions are well-founded and have a long-term effect on oral health as dental anxiety is a serious problem effects [13]. Avoiding the dentist can lead to worsening of dental disease, need for more complex procedures, and a greater need for emergency care4. It can also be fed to the underlying dental anxiety which is also known as the "vicious cycle of dental anxiety" $[4]$.

\section{Techniques to deal with anxiety in children}

Since the etiology of dental anxiety is multifactorial there is no monotherapy for its management [14]. Evaluating the patient and

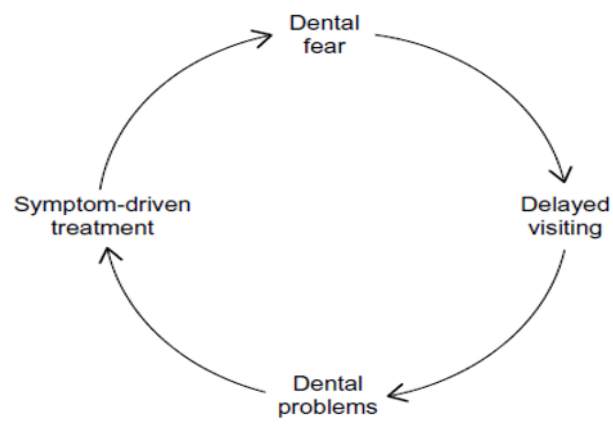

Figure 1: Vicious cycle of dental fear [14].

Note-Reproduced from Armfield JM, Stewart JF, Spencer AJ. The vicious cycle of dental fear: exploring the interplay between oral health, service utilization, and dental fear. BMC Oral Health. 2007:7:1 (http://creativecommons.org/license/2.0/) [14].

identifying the source and level of anxiety can help the dentist to formulate an appropriate treatment plan [14].

For children with a low level of anxiety the following approaches can be used [15]:

- Rapport building: Tell-show-do (TSD) technique is said to have good results while building a rapport with the child.

- Voice control: Moderately loud voice with deep tone is said to alleviate better response from children according to various studies.

- Distraction: Distractions like video-taped cartoons, audiotaped stories, and video games help in calming an anxious child.

- Modeling: The results are better when a child sees another child of the same gender and age going through the treatment without any adverse consequences.

- Memory reconstruction: This technique involves reconstructing a child's memory of the dental treatment using a positive image.

- Enhancing a sense of control: Preparing the children with the information about the dental treatment gives them a sense of control thus reducing anxiety. 
- Cognitive distraction: Encouraging the child to think of anything else other than the treatment is the cognitive distraction that helps in decreasing the anxiety.

Some of the coping techniques that can help adults with mild to moderate anxiety include [4]:

- Deep breathing

- Meditation

- Use of distraction in the form of music or screens

- Guided imagery

- Progressive muscle relaxants.

In the case of individuals with a high level of anxiety or dental phobia; laughing gas (Nitrous oxide), oral anxiolytics, conscious sedation, or general anesthesia can be used [4].

\section{Conclusion}

Dental anxiety can take its toll on anybody, be it, children, or adults. It not only causes the problem to the patient but to the dentist as well. For example, an anxious child will not allow the dentist to go ahead with a procedure as simple as screening. Patients with anxiety tend to salivate a lot which leads to improper isolation in turn increases the chances of failure of the treatment. The effect of anxiety is such that the dreams about losing teeth are one of the most interpreted dreams, usually indicating anxiety. With proper measures and a clear understanding of the level of anxiety, dentists can come up with a plan to treat the patient more effectively. Managing anxiety can be beneficial for the dentist to perform a smooth treatment and help the patient overcome the fear.

\section{Bibliography}

1. How the Fight or Flight Response Works.

2. International Studies Association.

3. What is anxiety?

4. Dental Anxiety and Phobia. Better health.

5. 3 Surprising Facts about Dental Phobia.

6. Caroline Campbell. "Dental Fear and Anxiety in Pediatric Patients. Practical Strategies to Help Children Cope.
7. DM De Menezes Abreu., et al. "Patterns of dental anxiety in children after sequential dental visits 12.6 (2011): 298-302.

8. The relationship between dental anxiety and dental pain in children aged 18 to 59 months: a study in Recife, Pernambuco State, Brazil.

9. M Majstorovic., et al. "Reliability and validity of measures used in assessing dental anxiety in 5- to 15-year-old Croatian children 4.4 (2003): 197-202.

10. Lyndsay C Bare., et al. "Strategies for Combating Dental Anxiety". The Journal of Dental Education 68.11 (2004): 1172-1177.

11. Santosh Kumar., et al. "Does dental anxiety influence oral health-related quality of life? Observations from a cross-sectional study among adults in Udaipur District". International Journal of Oral Science 51.2 (2009): 245-254.

12. Ng SKS and Leung WK. "A community study on the relationship of dental anxiety with oral health status and oral healthrelated quality of life". Community Dentistry and Oral Epidemiology 36.4 (2008): 347-356.

13. Keith M Milsom., et al. "The relationship between anxiety and dental experience in 5-year-old children". British Dental Journal (2003).

14. Deva Priya Appukuttan. "Strategies to manage patients with dental anxiety and dental phobia: literature review (2016).

15. T Newton., et al. "The management of dental anxiety: time for a sense of proportion?" The British Dental Journal 213.6 (2012): 271-274.

\section{Volume 5 Issue 9 September 2021 (C) All rights are reserved by Syeda Aafia Fathima.}

